\title{
Adherence in elderly patients with NCDs: Which is the best, educational or social support? A comparative study in Ecuador
}

Elizabeth Elena Aguirre Céspedes ( $\boldsymbol{\nabla}$ beth_med@hotmail.com )

Pontificia Universidad Catolica del Ecuador https://orcid.org/0000-0002-8736-9980

Angela Faydé Alfonso Florido

Pontificia Universidad Catolica del Ecuador

\section{Edgar León Segovia}

Pontificia Universidad Catolica del Ecuador

\section{Patricia Ortiz Solórzano}

Pontificia Universidad Catolica del Ecuador

Sergio Minué Lorenzo

Universidad de Granada

\section{Susana Alvear Durán}

Pontificia Universidad Catolica del Ecuador

\section{Galo Antonio Sánchez del Hierro}

Pontificia Universidad Catolica del Ecuador

\section{Research article}

Keywords: Adherence to treatment, non-adherence, adherence interventions, patient education, social support, family support.

Posted Date: September 2nd, 2019

DOI: https://doi.org/10.21203/rs.2.13600/v1

License: (a) (1) This work is licensed under a Creative Commons Attribution 4.0 International License. Read Full License 


\section{Abstract}

Background: Adherence to treatment is one of the mainstays of non-communicable diseases adequate control. Non - adherence can affect several aspects to both the patient and the health system. For this reason, it is important to have intervention strategies available to prevent detachment and improve adherence to treatment. The objective of this study is to evaluate the effectiveness of the educational strategy compared with the social and family support for the improvement of adherence in patients with chronic noncommunicable diseases. Methods: A quasi-experimental study was conducted in 159 participants with diagnosis of arterial hypertension or/and diabetes mellitus type 2 plus polypharmacy. Participants were divided in two groups and strategies: Group A: educational $(n=79)$ and Group B social/family support $(n=80)$, follow up three months for each group. For group "A", informative group workshops were assigned; while for group "B" therapeutic agreements were established. Adherence to treatment pre- and post-intervention were evaluated using the four item Morisky Green Levine scale of public domain. At the end of the intervention period, an intra and intergroup analysis were performed and a Z test for difference in proportions was applied; the RR was used as a measure of association, and Chi2 as a measure of significance. Results: A total of 152 patients complete the intervention. In group A, preintervention non-adherence was $58.2 \%$, post-intervention of $45.3 \%$ and final reduction of the failure was $12.9 \%(p<0,001)$. In group B, pre-intervention non-adherence was $55 \%$, post-intervention $46.8 \%$, and final reduction of adherence failure of $8.2 \%$, ( $p>0.05)$. Statistically significant difference was obtained between the decrease in the failure reached after the application of the educational strategy compared to social / family support strategy $(p=0.001)$. Conclusions: Educational strategy is more effective than social/family support strategy, to reduce the failure of therapeutic adherence. There was not association of sociodemographic factors and adherence to treatment.

\section{Background}

By 2001 adherence was defined by World Health Organization (WHO) as: "the extent to which the patient follows medical instructions". This definition presents some difficulties; the term "medical" does not describe the magnitude of the interventions that need to be used to treat chronic diseases. On the other hand, the word "instructions" leads the patient to be a passive actor receiving guidelines and advice, when must be an active entity throughout the treatment. Finally in 2003, WHO defined adherence as "the extent to which a person's behavior (taking medication, following a diet and/or making changes in lifestyle) corresponds to the recommendations agreed upon by a health care provider" using the previous concepts proposed by Haynes and Rand.[1,2,3]

Adherence behavior is the most important factor to assess the effectiveness of the prescribed therapeutic regimen in a patient with a chronic disease. In 2017, WHO reports that in the European Region is the most affected by noncommunicable diseases, these conditions account for an estimated $86 \%$ of the deaths and $77 \%$ of the disease and some of them as a result of non-adherence. In Europe is estimated that $20 \%$ to $30 \%$ of patients do not adhere to therapeutic short regimens, and when long-term medication is prescribed, $50 \%$ of patient are non-adherents.[4] 
Some researchers have studied the extent of non-adherence among certain medical conditions, indicating that only $51 \%$ of hypertension patients at the United States adhere to their prescribed drug treatment regimens. Also, nearly a half of all adults have at least one chronic disease, and the rate of nonadherence varies from $25 \%$ to $50 \%$, and it extends according to the characteristics of the patient, the disease and insurance coverage. $[5,6]$

Other interesting findings have been reported in Asia where the adherence percentage fluctuates according to the age found in diabetic patients: elderly group (28.1\%), middle-aged group (36.2\%) and younger group (51.8\%). Moreover, the mean adherence rate in people with hypertension on this population ranges from 50 to $70 \%$. [7,8]

In a study conducted in 7 cities in Latin America, adherence failure percentage was found that ranges from 30 to $40 \%$ in chronic diseases, such as arterial hypertension, diabetes and dyslipidemia.[9] However, in Ecuador the adherence average does not differ from another population, being of $51.7 \%$ reported in some clinical studies, which indicates that 1 out of 2 patients do not take the medication in the way that is considered appropriate.[10]

Adequate control of the most prevalent chronic diseases has become one of the main determinants for prevention of complications and premature deaths. It is estimated that approximately $40.8 \%$ of a certain captive population of diabetic patients in Ecuador has achieved good glycemic control, with an average glycosylated hemoglobin of $7.8 \pm 1.7 \%$.[11] Only $51.1 \%$ of the hypertensive population has an adequate blood pressure control level and more than two thirds of both diabetic and hypertensive population maintain inadequate control of their disease.[12]

Therefore, the main objective of the implementation of one or several adherence improvement strategies is to achieve therapeutic adherence to improve or eliminate unhealthy behaviors with the purpose of obtaining advantages in terms of quality of life and propose an impact favorable on the reduction of health costs. $[6,13]$ There are several studies that have demonstrated the effectiveness of interventions on adherence and the impact on the control and cost of the disease and its determinants. $[14,15,16]$

The improvement of therapeutic adherence should be an intermediate objective in the care of patients and not as a final goal. Despite the importance directed to the prevention and improvement of adherence, the final goal of medical practice should always be the adequate control of the disease, rehabilitation or as far as possible cure of the process, to provide a favorable quality of life of the patients.

The main objective of this study was to evaluate the effectiveness of the educational strategy compare with strategy of social and family support for the reduction of therapeutic adherence failure in elderly patients with hypertension or/and diabetes mellitus type 2 , and polypharmacy.

\section{Methods}


Study design: The study was a community quasi-experimental clinical trial, with pre- and postintervention analysis with two groups of captive population (group A and B), with a 3 months follow-up. The research protocol was approved by the Ethical Committee, Faculty of Medicine, Pontificia Universidad Católica del Ecuador (No. CB. 71 - 2018). The intervention process of both groups was carried out in the Hospital Padre Carollo, Quito - Ecuador.

Sample size: A simple size calculation, based on the study conducted by Al Mazroui and a universe of 753 patients, considering an expected difference of $32 \%$ in the intervention group and $18 \%$ in the control group. The calculated sample was 148 patients, with a significance of $95 \%$ and a error $=5 \%$. The total number of study participants was 159 , distributed in two groups, in a non-randomized way, as closely as possible: 79 participants for the Educational strategy group $(A)$ and 80 participants for the Social and family support strategy group (B).

Subjects: Elderly people attended in the outpatient clinic of the Hospital Padre Carollo; who met the inclusion criteria: age over 65 years, diagnosis of diabetes and / or hypertension plus polypharmacy (use of 3 or more drugs); that did not present exclusion criteria: severe physical and/or cognitive impairment that prevents participation in educational workshops and follow-up meetings and/or clinical complications of the disease: diabetic decompensation, hypertensive emergency that warrants hospital admission.

All subjects included in the study accepted their voluntary participation through informed consent.

Procedure for collecting information: A survey was used to obtain sociodemographic data, medical history, social support network. For the evaluation of adherence, the four item Morisky Green Levine scale, validated in 1986 and of public domain was used. It has a sensitivity of $93 \%$ and specificity of $53 \%$, in detection of therapeutic noncompliance.[17] It is a validated short questionnaire in patients with chronic diseases. Due to its sensitivity and the affordability of its practice, this test has become an easy tool to use in ambulatory level of care.[18,19]

An intervention was designated for each group during a planned time of three months (April - July 2018), after which the Morisky Green Levine scale was applied again to the participants of group A and B, categorizing the participants as adherent or no-adherent.

Interventions: Two strategies were designed. Strategy A: EDUCATIONAL: It is based on several techniques, in which both individual and group didactic approaches are carried out. Aimed the patient voluntarily adopting positive attitudes towards medication through the improvement of knowledge about illness, treatment and the importance of adherence.

The technique of group educational sessions was used, using verbal, audiovisual and written aids. Seven educational sessions were completed with an average duration of 30 - 45 minutes each, twice a month. Each session address different topics related to the importance of therapeutic adherence, strengthening in terms of knowledge and skills, regarding chronic disease and its treatment. In each of the workshops 
given, a record of attendance of the participants was kept. Five was the minimum number of attendances to establish as adequate for the intervention taking account $70 \%$ of assistance.

Strategy B: SOCIAL AND FAMILY SUPPORT: Includes interventions aimed to improve adherence through good social support, and mainly involving family members or their peers in the control of the disease to achieve proper management. It does not include Out-of-pocket spending or financial support.

The instrument of family contracts was used, with the aim of educating and agreeing therapeutic actions with the family or it pairs, in order to achieve compliance with the medical indications, with periodic, bimonthly follow-up to verify the achievement of agreements.

\section{Tracing:}

Intervention group A: The workshops were given every 2 weeks, completing a total of 7 workshops. In order to monitor the progress of the patient within the program, their condition and health status, weekly telephone calls were made and a total of 3 medical appointments were completed. Those who did not complete the minimum of 5 assistances were excluded from the study.

Intervention group B: It was carried out through weekly telephone contacts and three medical appointments during the whole process, in order to monitor the disease, assess the progress and fulfillment of the family contract. After completing the planned intervention time, those participants from whom the contact was lost were excluded from the study and therefore verification of compliance with the therapeutic contract.

During the follow-up period, no new rescue interventions were performed to improve adherence; only the advances made in each group were evaluated.

Data analysis: A database was created in Microsoft Excel 2016; statistical analysis was performed using the SPSS software package version 25 and the EpiData software version 3.1. Descriptive analysis, quantitative means and standard deviations were obtained. For bi-varial analysis, Relative Risk (RR) was used as a measure of association and Chi square $\left(X^{2}\right)$ as a hypothesis test, $A$ p-Value of $<0.05$ was considered statistically significant. For quantitative variables the Kolmogorov normality test was applied; using the T-Student for normal distribution, and the Mann-Whitney $U$ for those with asymmetric distribution. For the intragroup and intergroup analysis, the $Z$ test was used to differentiate proportions, as a test of statistical significance.

\section{Results}

A total of 159 participants from 231 met the inclusion criteria and were divided into two groups: group A $(n=79)$ and group $B(n=80)$. Throughout the intervention, losses were registered in both groups: 7 patients from group $A$ and 4 from group $B$. Figure 1 illustrate the selection and distribution of participants during the investigation. The sociodemographic and clinic characteristics of both groups are presented in 
Table 1. The statistical analysis showed that the groups were heterogeneous in relation to gender, previous diagnosis, time of diagnosis of the disease and number of doses of medications per day, with $p>0.05$; however, in these variables no significant risk association was found that influences the final adherence result.

Table 1: Baseline sociodemographic and clinical characteristics according to intervention groups

\begin{tabular}{|l|l|l|l|}
\hline Characteristics / Groups & $\begin{array}{l}\text { Group A } \\
\text { (n=79) }\end{array}$ & Group B (n=80) & $\begin{array}{l}\mathbf{p} \\
\text { Value }\end{array}$ \\
\hline Age (years mean) & $\begin{array}{l}71.06(\mathrm{SD} \\
6,37)\end{array}$ & $69.44(\mathrm{SD} 6,03)$ & \\
\hline $60-74$ & $58(46.8 \%)$ & $66(53.2 \%)$ & 0.101 \\
\hline$>75$ & $21(60 \%)$ & $14(40 \%)$ & \\
\hline Gender & & & \\
\hline Female & $48(60.8 \%)$ & $34(42.5 \%)$ & 0.021 \\
\hline Male & $31(39.2 \%)$ & $46(57.5 \%)$ & \\
\hline Scholarship & & & 0.119 \\
\hline None / Primary & $55(69.6 \%)$ & $43(53.8 \%)$ & \\
\hline Secondary/ Technical education & $16(20.3 \%)$ & $24(30.0 \%)$ & \\
\hline Higher education & $8(10.1 \%)$ & $13(16.3 \%)$ & \\
\hline Who does he/she live with & & & 0.108 \\
\hline Alone & $11(13.9 \%)$ & $5(6.3 \%)$ & \\
\hline Family / similes & $68(86.1 \%)$ & $75(93.8 \%)$ & \\
\hline Provenance & & & 0.318 \\
\hline Urban & $59(74.7 \%)$ & $54(67.5 \%)$ & \\
\hline Rural & $20(25.3 \%)$ & $26(32.5 \%)$ & \\
\hline Previous diagnosis & & & 0.001 \\
\hline Arterial hypertension & $45(57 \%)$ & $56(70 \%)$ & \\
\hline Diabetes Mellitus 2 & $16(20.2 \%)$ & $1(1.25 \%)$ & \\
\hline Both Diabetes and Hypertension & $18(22.8 \%)$ & $23(28.75 \%)$ & \\
\hline Get help for the administration of medicine & & & 0.921 \\
\hline Receive help & $23(29.1 \%)$ & $31(38.8 \%)$ & 0.200 \\
\hline Don't receives help & $56(70.9 \%)$ & $49(61.3 \%)$ & \\
\hline Time of diagnostic in months (mean) & $94.7(\mathrm{DS} 87.6)$ & $176.55(\mathrm{DS}$ & $95.7)$ \\
\hline Number of drugs per day (mean) & & $3.30(\mathrm{DS} 0.53)$ & \\
\hline $\begin{array}{l}\text { Number of medication intakes per day } \\
\text { (mean) }\end{array}$ & $3.29(\mathrm{DS} 0.58)$ & \\
\hline
\end{tabular}

Adherence to treatment: Adherence measurement in both groups was performed by applying the Morisky - Green test; the failure of pre-intervention adherence obtained in group A was $58.2 \%(n=46)$ of $55 \%(n=$ $44)$ in group $B(p=0.681)$. The postintervention results of adherence failure were $45.3 \%(n=34)$ and 
46.8\% $(n=36)$ for group A and B respectively $(p=0.861)$; demonstrating by the value of $p$ the homogeneity between the groups.

Table 2 shows the calculation of the difference in proportions of the therapeutic adherence failure for each one of the groups through the application of a $Z$ test, during the pre- and post-intervention; $12.9 \%$ in group $\mathrm{A}(p=0.15)$ and $8.3 \%$ in group $\mathrm{B}$, without statistically significant differences for both groups $(p=$ $0.38)$.

Table 2: Table of difference of proportions of failure of therapeutic adherence before and after intra-group intervention: GROUP A and B.

\begin{tabular}{|c|c|c|c|c|}
\hline \multicolumn{5}{|c|}{ GROUP A (EDUCATIONAL STRATEGY) } \\
\hline $\begin{array}{r}\text { Failure of therapeutic } \\
\text { adherence }\end{array}$ & $\begin{array}{l}\text { Pre-intervention } \\
(\mathrm{n}=79)\end{array}$ & $\begin{array}{c}\text { Post- } \\
\text { intervention } \\
(\mathrm{n}=75)\end{array}$ & $\begin{array}{c}\text { Difference of } \\
\text { proportions (\%) }\end{array}$ & $\begin{array}{r}P \\
\text { value* }\end{array}$ \\
\hline Number of cases (\%) & $46(58,2 \%)$ & $34(45,3 \%)$ & $\begin{array}{c}0,129(12.9) \\
\text { IC }-0,04-0,29\end{array}$ & 0,15 \\
\hline \multicolumn{5}{|c|}{ GROUP B (SOCIAL AND FAMILY SUPPORT STRATEGY) } \\
\hline $\begin{array}{r}\text { Failure of therapeutic } \\
\text { adherence }\end{array}$ & $\begin{array}{l}\text { Pre-intervention } \\
(\mathrm{n}=80)\end{array}$ & $\begin{array}{c}\text { Post- } \\
\text { intervention } \\
(\mathrm{n}=77)\end{array}$ & $\begin{array}{c}\text { Difference of } \\
\text { proportions (\%) }\end{array}$ & $\begin{array}{r}P \\
\text { value* }\end{array}$ \\
\hline Number of cases (\%) & $44(55 \%)$ & $36(46,7 \%)$ & $\begin{array}{c}0,083(8.3) \\
\text { IC }-0,08-0,25\end{array}$ & 0,38 \\
\hline
\end{tabular}

Moreover, a statistically significant difference was found between the decrease in failure reached after the application of the educational strategy compared with the social and family support strategy. (Adjusted RR 3.1 ( $\mathrm{Cl} 1.6$ - 6.2) p=0.001). Observing a greater decrease of the failure with the implementation of the educational strategy (group $A$ ) in comparison with the strategy of social and family support (group B). (Adjusted RR 11.27 (CI 2.9 - 43.5) p 0.000). (Table 3)

Table 3: Comparison intergroup of the therapeutic adherence failure. 


\begin{tabular}{|c|c|c|c|c|c|c|}
\hline & \multicolumn{3}{|c|}{ Pre-intervention } & \multicolumn{3}{|c|}{ Post-intervention } \\
\hline & $\begin{array}{c}\text { Non- } \\
\text { adherents }\end{array}$ & $\mathrm{RR}$ & $\begin{array}{c}\mathrm{P} \\
\text { value }\end{array}$ & $\begin{array}{c}\text { Non- } \\
\text { adherents }\end{array}$ & $\mathrm{RR}$ & $\begin{array}{r}P \\
\text { Value }\end{array}$ \\
\hline \multirow[t]{2}{*}{$\begin{array}{c}\text { Group } \\
\text { A }\end{array}$} & \multirow[t]{2}{*}{$\begin{array}{l}46 / 79 \\
(58,2 \%)\end{array}$} & $\begin{array}{c}\text { RR 1,14 } \\
\text { (IC 0,60-2,13) }\end{array}$ & $\begin{array}{r}p \\
0,681\end{array}$ & \multirow[t]{2}{*}{$\begin{array}{c}34 / 75 \\
(45,3 \%)\end{array}$} & $\begin{array}{l}\text { RR 0,944 } \\
\text { (IC 0,49- }\end{array}$ & $\begin{array}{r}p \\
0,861\end{array}$ \\
\hline & & $\begin{array}{c}\text { Adjusted RR 38,6 } \\
\text { (IC 7,9-187,5) }\end{array}$ & $\begin{array}{r}p p \\
0,000\end{array}$ & & $\begin{array}{c}\text { Adjusted RR } \\
11,27 \\
(\mathrm{IC} 2,9- \\
43,5)\end{array}$ & $\begin{array}{r}p \\
0,000\end{array}$ \\
\hline \multirow[t]{2}{*}{$\begin{array}{c}\text { Group } \\
\text { B }\end{array}$} & \multirow[t]{2}{*}{$\begin{array}{l}44 / 80 \\
(55 \%)\end{array}$} & $\begin{array}{c}\text { RR 1,14 } \\
(\text { IC } 0,60-2,13)\end{array}$ & $\begin{array}{r}p \\
0,681\end{array}$ & $\begin{array}{l}36 / 77 \\
(46,7 \%)\end{array}$ & $\begin{array}{c}\text { RR 0,944 } \\
(\mathrm{IC} 0,49- \\
1,78)\end{array}$ & $\begin{array}{r}p \\
0,861\end{array}$ \\
\hline & & $\begin{array}{c}\text { Adjusted RR 0,708 (IC } \\
0,28-1,74)\end{array}$ & $\begin{array}{r}p \\
0,453\end{array}$ & & $\begin{array}{c}\text { Adjusted RR } \\
0,833 \\
\text { (IC 0,51-1,3) }\end{array}$ & $\begin{array}{r}p \\
0,453\end{array}$ \\
\hline Total & $\begin{array}{l}90 / 159 \\
(56,6 \%)\end{array}$ & & & $\begin{array}{c}70 / 152 \\
(46 \%)\end{array}$ & $\begin{array}{l}\text { Total RR 3,1 } \\
\text { (IC 1,6 - 6,2) }\end{array}$ & $\begin{array}{r}p \\
0,001\end{array}$ \\
\hline
\end{tabular}

\section{Discussion}

Adherence represents a great challenge for the health system, due to the increase in the incidence of chronic noncommunicable diseases in the elderly population, being this one the most susceptible to suffer the consequences of poor adherence. The results of this study allow to demonstrate that the timely implementation of an educational strategy contributes in the long term to the improvement of adherence; since it optimizes the knowledge about illness and treatment, generating an individual empowerment.

More than $50 \%$ of the study participants do not adhere to the prescribed treatment (58.2\% group A and $55 \%$ group B). The lack of adherence to therapeutic treatment is one of the situations that is manifested as usual in clinical practice, as shown by several studies, reporting a failure of adherence between $40 \%$ $50 \%$ and in some cases even greater than $55 \% .[20,21,22]$

Educational strategy decreased the failure rate by $12.9 \%$ compared to $8.3 \%$ in the social and family support strategy group $(p<0,05)$. These results are comparable with the prospective, interventional study by Adepu et al. conducted in the Medicine Outpatient Department, in which it obtained a $15 \%$ decrease in adherence failure in the intervention group, after the application of a 3-month educational strategy.[23] Some other studies also corroborate these findings, such as the meta-analysis conducted by Milosavljevic, in which, of a total of 65 articles reviewed, 22 studies show a $61.5 \%$ improvement in adherence, in favor of the educational intervention group (counseling person - person, with detailed knowledge about disease prevention and management) compared to the control group (regular advice provided with the medical prescription), with significant results $(p<0.05)$.[24] 
Previous systematic reviews have shown that the highest percentage of adherence failure reduction linked to an educational intervention strategy is $45.5 \%$ and the lowest is $4,8 \%$. In the following Table 4 a comparison is made between the studies carried out on the measurement of adherence.

Several studies have attempted to demonstrate the beneficial effect of implementing strategies for the improvement of therapeutic adherence, either as a single strategy or as a combination of these; mainly using techniques of educational reinforcement, counseling (including motivational interview or cognitivebehavioral therapy), and additional support from family or partners. $[14,15,16]$

Table 4: Comparison of the effectiveness of educational interventions in the reduction of therapeutic adherence failure.

\begin{tabular}{|c|c|c|c|c|c|c|}
\hline $\begin{array}{l}\text { Study } \\
\text { (year) }\end{array}$ & $\begin{array}{l}\text { Study } \\
\text { design }\end{array}$ & $\begin{array}{c}\text { Type of } \\
\text { intervention }\end{array}$ & $\begin{array}{l}\text { Duration } \\
\text { (months) }\end{array}$ & $\begin{array}{l}\text { Initial /Final } \\
\text { failure } \\
\text { measurement }\end{array}$ & $\begin{array}{l}\text { Reduction } \\
\text { of } \\
\text { adhesion } \\
\text { failure }\end{array}$ & $\mathrm{P}$ value \\
\hline $\begin{array}{l}\text { Al Mazroui } \\
\text { et al., } \\
\text { 2009.[25] }\end{array}$ & RCT & $\begin{array}{l}\text { Educational } \\
\text { about illness. }\end{array}$ & 12 & $\begin{array}{r}48,3 \%- \\
32,5 \%\end{array}$ & $26,9 \%$ & $\mathrm{p}=0,003$ \\
\hline $\begin{array}{l}\text { Babamoto } \\
\text { et al., } \\
\text { 2009.[26] }\end{array}$ & RCT & $\begin{array}{l}\text { Educational } \\
\text { about disease and } \\
\text { monitoring } \\
\text { devices. }\end{array}$ & 6 & $45 \%-23 \%$ & $22 \%$ & $p<0,05$ \\
\hline $\begin{array}{l}\text { Tan et al., } \\
\text { 2011. [27] }\end{array}$ & RCT & $\begin{array}{l}\text { Educational } \\
\text { about illness and } \\
\text { self-control. }\end{array}$ & 3 & $\begin{array}{r}15,5 \%- \\
10,7 \%\end{array}$ & $4,8 \%$ & $\mathrm{p}=0,008$ \\
\hline $\begin{array}{l}\text { Jarab et } \\
\text { al., } 2012 . \\
{[28]}\end{array}$ & RCT & $\begin{array}{l}\text { Educational } \\
\text { about illness and } \\
\text { treatment. }\end{array}$ & 6 & $\begin{array}{r}74,1 \%- \\
28,6 \%\end{array}$ & $45,5 \%$ & $\mathrm{p}=0,003$ \\
\hline $\begin{array}{l}\text { Bogner et } \\
\text { al., 2012. } \\
{[29]}\end{array}$ & RCT & $\begin{array}{l}\text { Educational } \\
\text { about illness and } \\
\text { community work. }\end{array}$ & 3 & $58 \%-39 \%$ & $19 \%$ & $\mathrm{p}<0,001$ \\
\hline $\begin{array}{l}\text { Butt et al, } \\
\text { 2016.[30] }\end{array}$ & RCT & $\begin{array}{l}\text { Educational } \\
\text { about illness. }\end{array}$ & 9 & $\begin{array}{r}57,6 \%- \\
30,3 \%\end{array}$ & $27,3 \%$ & $\mathrm{p}=0,02$ \\
\hline
\end{tabular}

An interesting finding on this study was related to "helping patients to administering medication", since this decreases the probability risk of presenting failure to adhere to treatment (Group A RR 0.70 - Group B RR 0.49); concordant with results of other studies showing that low social support is a risk factor for lack of adherence to therapeutic indications and contributes to an increase in cardiovascular risk.[31]

\section{Conclusions}


Present study was able to demonstrate that the educational strategy turned out to be more effective than social and family support strategy, to decrease the non-adherence. Results attributable to the premise that the improvement of information that patients have about their disease, treatment, risk factors and self-care; are an important starting point, since it contributes to the patient mentality change, ceasing to be a passive actor receiving indications, to be an active part of the integral management process. This is one of the main objectives of the Chronic Care Model of Care implemented by the Pan American Health Organization.[32]

To achieve improvements in adherence, is required an interdisciplinary health team and a chronic care model within the local health system to deal effectively with non-communicable conditions; being the family doctor who must lead the application of strategies that encourage a good adherence; with an integrating vision, that includes all the actors: patient, family and medical team in the process. To diminish the own complications derived from the disease and the sanitary cost, being necessary, to implement available strategies (educational, behavioral, therapeutic, social, combined) to improve or maintain an adequate adherence to the treatment, being a combination of these, the best option.

\section{Limitations}

The present study did not consider the out of pocket or financial support for medication of each one of patients. However, access to medicines is not enough to reduce the burden of chronic diseases, according to the World Health Organization.

\section{List Of Abbreviations}

WHO: World Health Organization

RCT: Randomized Clinical Trial.

\section{Declarations}

Ethics approval and consent to participate: All participants included in this study voluntarily accepted their participation by signing the respective written informed consent; with subsequent approval by the Bioethics Committee of the Pontifical Catholic University of Ecuador (No. CB. 71 - 2018).

Consent for publication: Not applicable.

Availability of data and materials: The material and statistical data used for the preparation of this study are available from the corresponding author upon reasonable request.

Funding. Not applicable

Competing of interest: The authors report they have no conflicts of interest with regards to the publication of this manuscript. 
Author Contributions: EA, AA, EL, PO and GS took part in the concept and design of research. EA, AA on acquisition of data; $E A, A A, P O$ and GS on the analysis and interpretation of data; EA, GS, SM, SA in the preparation of the manuscript. All authors critically revised and approved the final manuscript.

Acknowledgments: The authors are grateful to the participants as well as the staff of the Hospital Padre Carollo.

\section{References}

1. Haynes RB, Taylor DW, Sackett DL, Gibson ES, Bernholz CD, Mukherjee J. Can simple clinical measurements detect patient noncompliance? Hypertension. 1980;2(6):757-764.

2. Rand CS. Measuring adherence with therapy for chronic diseases: Implications for the treatment of heterozygous familial hypercholesterolemia. Am J Cardiol. 1993;72(10).

3. De Geest S, Sabaté E. Adherence to Long-Term Therapies: Evidence for Action. Eur J Cardiovasc Nurs. 2001;2(4):323-323.

4. Pharmaceutical Group of the European Union (PGEU). Targeting Adherence. Improving Patient Outcomes in Europe through Community Pharmacists' Intervention. Brussels; 2008.

5. Kozma CM. The role of medication adherence. Managed care interface. 1998;11(9):64, 66.

6. Tiede DM, Prince RC, Dutton PL. EPR and optical spectroscopic properites of the electron carrier intermediate between the reaction center bacteriochlorophylls and the primary acceptor in Chromatium vinosum. Biochim Biophys Acta - Bioenerg. 1976;449(3):447-467.

7. Chen S-L, Tsai J-C, Lee W-L. The impact of illness perception on adherence to therapeutic regimens of patients with hypertension in Taiwan. J Clin Nurs. 2009;18(15):2234-2244.

8. Shams MEE, Barakat EAME. Measuring the rate of therapeutic adherence among outpatients with T2DM in Egypt. Saudi Pharm J. 2010;18(4):225-232.

9. Silva H, Hernandez-Hernandez R, Vinueza R, et al. Cardiovascular Risk Awareness, Treatment, and Control in Urban Latin America. Am J Ther. 2010;17(2):159-166.

10. Conthe P, Márquez Contreras E, Aliaga Pérez A, et al. Adherencia terapéutica en la enfermedad crónica: estado de la situación y perspectiva de futuro. Rev Clínica Española. 2014;214(6):336-344.

11. Aguinaga G, Barrera F. Determinación de factores que afectan la adherencia al tratamiento en pacientes con Diabetes Mellitus 2, que acuden a un club de diabéticos. Rev Fac Cienc Med. 2014;39(1):69-78.

12. Ortiz R, Joanna J, Quintero R, Hospital W. Prevalencia de hipertensión arterial en individuos adultos de las parroquias urbanas de la ciudad de Cuenca, Ecuador. Sindrome Cardiometabolico, 2014;IV (1): $10-21$

13. Holguín L, Correa D, Arrivillaga M, Cáceres D, Varela M. Adherencia al tratamiento de hipertensión arterial: efectividad de un programa de intervención biopsicosocial. Univ Psychol. 2006;5(3):535-547. 
14. Santschi V, Chiolero A, Paradis G, Colosimo AL, Burnand B. Pharmacist Interventions to Improve Cardiovascular Disease Risk Factors in Diabetes: A systematic review and meta-analysis of randomized controlled trials. Diabetes Care. 2012;35(12):2706-2717.

15. Santschi V, Chiolero A, Colosimo AL, et al. Improving Blood Pressure Control Through Pharmacist Interventions: A Meta-Analysis of Randomized Controlled Trials. J Am Heart Assoc. 2014;3(2):e000718-e000718.

16. Antoine S-L, Pieper D, Mathes T, Eikermann M. Improving the adherence of type 2 diabetes mellitus patients with pharmacy care: a systematic review of randomized controlled trials. BMC Endocr Disord. 2014;14(1):53.

17. Moon SJ, Lee WY, Hwang JS, Hong YP, Morisky DE. Accuracy of a screening tool for medication adherence: A systematic review and meta-analysis of the Morisky Medication Adherence Scale-8. PLoS One. 2017;12(11):1-18.

18. Magalhães ALP, Erdmann AL, Silva EL da, Santos JLG dos. Lean thinking in health and nursing: an integrative literature review. Rev Lat Am Enfermagem. 2016;24(1):52-61.

19. Rodríguez Chamorro MÁ, García-Jiménez E, Gil AB, et al. Herramientas para identificar el incumplimiento farmacoterapéutico desde la farmacia comunitaria. Pharmaceutical Care España 2009; 11(4): 183-191

20. Heydari H, Kamran A, Ahari Ss, Biria M, Malepour A. Determinants of patient's adherence to hypertension medications: Application of health belief model among rural patients. Ann Med Health Sci Res. 2014;4(6):922.

21. Chiluiza Ramírez, M. Factores que influyen sobre la adherencia terapéutica en la hipertensión arterial, Parroquia San Andrés. 2016. oai:repositorio.uta.edu.ec:123456789/24240

22. Viswanathan M, Golin CE, Jones CD, Ashok M, Blalock SJ, Wines RCM, et al. Interventions to improve adherence to self-administered medications for chronic diseases in the United States: a systematic review. Annals of internal medicine. 2012;157:785-95.

23. Adepu R, Ari SM. Influence of structured patient education on therapeutic outcomes in diabetes and hypertensive patients. Asian J Pharm Clin Res. 2010;3(3):174-178

24. Milosavljevic A, Aspden T, Harrison J. Community pharmacist-led interventions and their impact on patients' medication adherence and other health outcomes: a systematic review. Int J Pharm Pract. June 2018:1-11.

25. Al Mazroui NR, Kamal MM, Ghabash NM, Yacout TA, Kole PL, McElnay JC. Influence of pharmaceutical care on health outcomes in patients with Type 2 diabetes mellitus. Br J Clin Pharmacol. 2009;67(5):547-557.

26. Babamoto KS, Sey KA, Camilleri AJ, Karlan VJ, Catalasan J, Morisky DE. Improving Diabetes Care and Health Measures Among Hispanics Using Community Health Workers. Heal Educ Behav. 2009;36(1):113-126.

27. Tan MY, Magarey JM, Chee SS, Lee LF, Tan MH. A brief structured education programme enhances self-care practices and improves glycaemic control in Malaysians with poorly controlled diabetes. 
Health Educ Res. 2011;26(5):896-907.

28. Jarab AS, Alqudah SG, Mukattash TL, Shattat G, Al-Qirim T. Randomized Controlled Trial of Clinical Pharmacy Management of Patients with Type 2 Diabetes in an Outpatient Diabetes Clinic in Jordan. J Manag Care Pharm. 2012;18(7):516-526.

29. Bogner HR, Morales KH, de Vries HF, Cappola AR. Integrated Management of Type 2 Diabetes Mellitus and Depression Treatment to Improve Medication Adherence: A Randomized Controlled Trial. Ann Fam Med. 2012;10(1):15-22.

30. Butt M, Mhd Ali A, Bakry MM, Mustafa N. Impact of a pharmacist led diabetes mellitus intervention on $\mathrm{HbA} 1 \mathrm{c}$, medication adherence and quality of life: A randomised controlled study. Saudi Pharm J. 2016;24(1):40-48.

31. Aggarwal B, Liao M, Allegrante JP, Mosca L. Low Social Support Level is Associated with NonAdherence to Diet at 1 Year in the Family Intervention Trial for Heart Health (FIT Heart). J Nutr Educ Behav. 2010;42(6):380-388.

32. Organización Panamericana de la Salud, Organización Mundial de la Salud. Estrategia Para La Prevención y El Control de Las Enfermedades No Transmisibles. Washington; 2012.

\section{Figures}




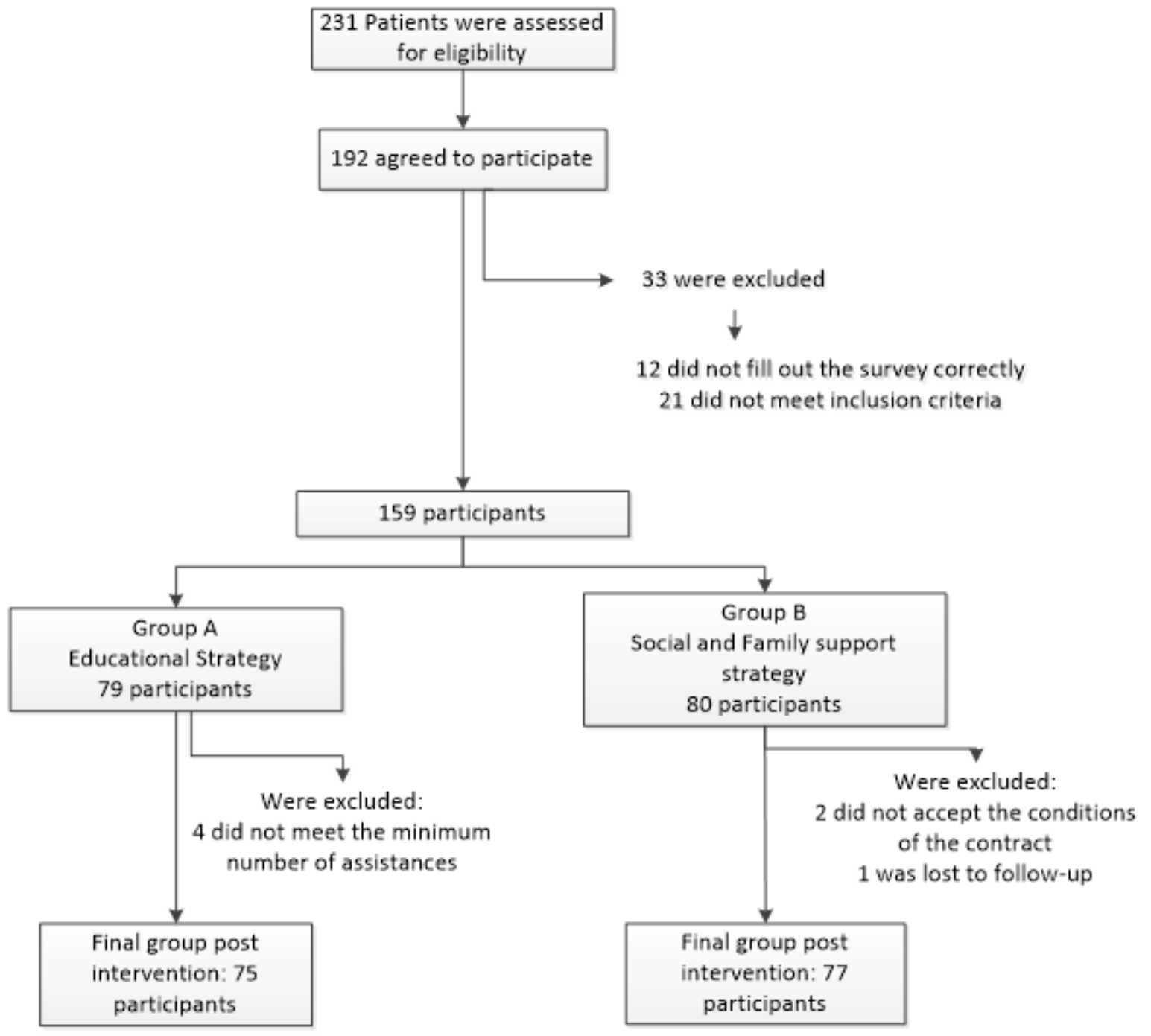

\section{Figure 1}

Selection and distribution of participants. 